\title{
Current Status of the 2nd Generation of Intact Stability: Investigation of the Pure Loss of Stability and Parametric Roll Mode
}

\author{
Jaeho Chung ${ }^{\circledR 1}$, Dong Min Shin $\circledast^{2}$, Won-Don Kim $\circledast^{3}$ and Byung Young Moon $\circledast^{4}$ \\ ${ }^{1}$ Research Professor, Security Convergence Institute, Korea Advanced Institute of Science and Technology (KAIST), Daejeon, Korea \\ ${ }^{2}$ Research Professor, Shipbuilding \& Ocean Equipment Industry Empowerment Center, Kunsan National University, Gunsan, Korea \\ ${ }^{3}$ President, Marine Tech-In Co.,Ltd., Busan, Korea \\ ${ }^{4}$ Professor, Shipbuilding \& Ocean Equipment Industry Empowerment Center, Kunsan National University, Gunsan, Korea
}

KEY WORDS: Parametric roll, Pure loss of stability, Direct stability assessment(DSA), 2nd generation of second generation intact stability criteria, International Maritime Organization(IMO)

ABSTRACT: A review of the 2nd generation of intact stability by the International Maritime Organization is performed. The main issues with the new stability criteria are reviewed. In particular, the physical background and related mathematical formulations of the pure loss of stability and parametric roll are summarized. Based on a literature review, benchmark calculation results for 17 different types of ships are discussed, and the final results are in excellent agreement with our physical expectations. Some relatively serious design problems are found in the application of the new stability criteria to sample ships built in Korea, and possible technical solutions are proposed, which have to be improved in the coming years.

\section{Introduction}

\subsection{Background of study}

The behavior of ships in waves is a very important issue related to the safety of ships, and the International Maritime Organization (IMO) is working to ensure safer maritime movements by establishing intact stability criteria for the safe operation of vessels and applying them to all vessels. As part of this effort, the IMO has been developing the Second Generation Intact Stability Criteria (SGISC) and preparing to apply them to all vessels for over a decade. The IMO is known to be in the final development stages for new stability criteria, with the aim of implementing these criteria after 2020 (Belenky et al., 2011; Peters et al., 2011; Chouliaras, 2014).

The first intact stability criteria were introduced by the Maritime Safety Committee (MSC) as the Intact Stability (IS) code (2008) and came into force in 2010. This first generation intact stability criteria were based on Rahola's work (1939), and a weather criterion was added to the criteria in the 1950s. The SGISC were launched in 2002 by the subcommittee on Stability and Load Lines and on Fishing Vessels Safety (SLF) under IMO, but the practical application began in 2005 .

The most fundamental reason for the development of new stability criteria is that accidents also occur on ships that meet existing stability criteria. The accident that affected an American President Lines (APL) ship in 1998, as shown in Fig. 1, is a typical example. Countermeasures to these accidents (ABS, 2004) were discussed separately before the discussion of the IMO second generation intact stability criteria. However, because these accidents do not occur frequently, it seems impossible to find their causes and develop countermeasures based on experience. Thus, it seems reasonable to think about more quantitative and systematic countermeasures. In particular, as the rapidly changing shipping industry has begun to buildships of previously non-existent size, problems that cannot be

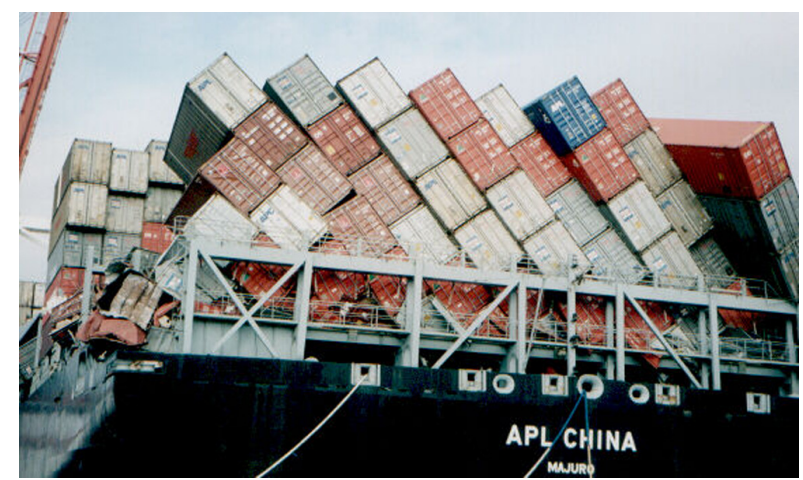

Fig. 1 APL China accident, 1998

Received 28 May 2019, revised 13 February 2020, accepted 14 February 2020

Corresponding author Byung Young Moon: +82-62-469-1854, moonby@kunsan.ac.kr

(c) 2020, The Korean Society of Ocean Engineers

This is an open access article distributed under the terms of the creative commons attribution non-commercial license (http://creativecommons.org/licenses/by-nc/4.0) which permits unrestricted non-commercial use, distribution, and reproduction in any medium, provided the original work is properly cited. 
solved empirically have arisen. For this reason, the IMO has formed a group of experts from around the world to develop new stability criteria, and much debate has taken place over the last decade.

When new stability criteria are implemented, new ships are more likely to have reduced onboard cargo volumes in comparison to existing ships. In the case of existing ships, there is a great possibility that they will be forced to decrease their onboard cargo volume or operating speed, which is expected to have a large impact on future ship operations. Because the shipbuilding industry accounts for a large portion of the Korean economy, and the Korean shipbuilding industry accounts for a very large share of the world's shipbuilding industry, it is necessary to pay attention to the design changes that will occur when the new stability criteria come into effect. However, to date, there has been no full-scale research on the intact stability criteria in Korea. When new stability criteria with greater safety are put in force, they are expected to be more restrictive in terms of the speed and loading conditions than the current ship criteria, which means that more ships will need to be built than at present. As a result, it seems to be very positive. In particular, among the large ships, the types of ships most affected by the reinforcement of the stability criteria at present are considered to be container ships, RoRo ships, RoPax, and cruise ships with a relatively high center of gravity. From the Korean shipbuilder's perspective, more careful consideration should be given to whether or not to change the design of large container ships, which have secured international competitiveness for Korean shipbuilders.

This paper introduces the SGISC being developed by IMO and illustrates their mathematical modeling and solution method. In addition, the new design environment or design methods are discussed, including the technical limitations that occur when actually applied to ships. Finally, the operational constraints of the existing ships and the possibility of design changes are discussed by applying the new criteria to the small and medium-sized container chips actually being constructed in Korea in order to provide actual technical discussions based on the new criteria.

\subsection{Current status of IMO Second Generation Intact Stability Criteria study}

As seen in Uzunoglu (2011), Peters et al. (2011), Umeda (2013), Krüger et al. (2013), and Grinnaert (2017), the SGISC that have been discussed so far consist of a three-stage verification process and one operation guide, as shown in Fig. 2. This verification test is also expected to be applied to the ship stability criteria (IS 2008) currently in force, and it is known that any ship that does not pass this process will not be able to operate. Therefore, the new stability criteria should be satisfied for the operation of ships.

The SGISC include a multi-stage verification process to minimize the cost required for the calculations needed to apply the criteria. The SGISC currently under development are intended for ships longer than $24 \mathrm{~m}$ in length. If a very detailed calculation criterion is provided for a large number of ships, it is expected that performing the calculation for the criterion application will be impossible within a practical time

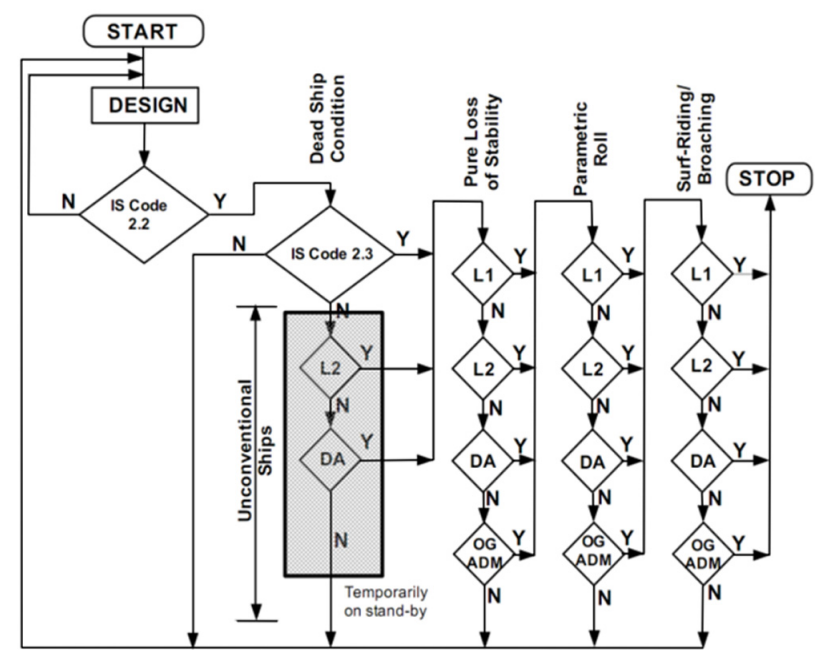

Fig. 2 Second Generation Intact Stability Criteria (SGISC) diagram

limit because the number of target ships is very large. A multi-stage application criterion was introduced to actually reduce the calculation demand for applying the criterion by using a method that does not perform a detailed calculation again when the margin of stability has been established through a simple calculation.

The first two stages of the ongoing $3+1$ stage structure of the SGISC are called the "vulnerability assessment" stages, which are based on a simple empirical formula. The vulnerability decision at this stage is not conclusive, but it means that the ship is likely to lose stability in the sea, and that the ship has weak stability in the sea. In fact, the largest logical difficulty in establishing the stability criteria lies in the problem of the rarity of ship accidents related to stability. Thus, it is considered to be reasonable to approach the stability criteria probabilistically. As shown in Fig. 2, the implementation of the SGISC does not abolish the existing Stability Criteria (IS 2008 2.3), but involves the concept of adding additional criteria to the existing criteria. Thus, the existing stability criteria do not disappear. Therefore, all of the data related to the existing stability calculations will be meaningful and will not be discarded. The newly added part of the stability criteria consists of a structure that authenticates the stability of the ship when the criteria in each mode are passed after applying multi-layered criteria for each independent inspection mode.

Because such existing methods often report logically contradictory results, efforts have been made to solve this problem. For example, satisfying the level-1 criteria means satisfying the level-2 criteria as well, but, in the case of verification through actual calculations, sometimes contradictory results may be obtained. As a result, efforts to find realistic measures to solve this logical contradiction have continued. Until now, most of the research and discussions related to stability have been focused on levels 1 and 2, and the opinions about the criteria have significantly coincided. Thus, the final work is proceeding with the aim of finalizing the criteria in 2020. The most complex level of verification is level 3, where the stability calculation is performed at the most complex level. This is called a "direct stability assessment" (DSA), which is also closely related to the 
development of the ship's own operational guidance.

Performing model experiments in the DSA part is a very expensive task. In general, conducting model experiments is unrealistic, and the demand for direct stability assessment by computer simulation is expected to increase. Therefore, it is considered that active measures for these problems are required.

Because the IMO's criteria for second generation intact stability have not been established, the criteria discussed in this paper are not exhaustive regulations and may be changed later. Accordingly, the conclusions presented here may vary. However, when looking at the discussion so far, the stability criteria are based on physical phenomena and established through mathematical modeling and rational simplification. As a result, their fundamental structures do not appear to change, but the criteria are likely to be strengthened or mitigated by changing certain criteria values. In addition, the errors that may occur in the application of the simplified reference equation can be corrected when the high-level direct evaluation method is implemented even if the low-level provisions of the vulnerability standard are unreasonable.

\section{Vulnerability to stability loss mode}

When a hull is assumed to be a rigid body, its motion has six degrees of freedom. In ships with a typical shape, most of the movement displacement is very small compared to the length of the hull, but the rolling value should not be underestimated. Because the overturning of a ship in waves is usually caused by a large rolling value, the most important element of a ship's movement is its roll. Therefore, most ship stability assessments focus on the calculation of the roll. The IMO defines the vulnerable stability status for the following five modes, and levels 1 and 2 of each mode are defined in Table 1.

The activities of the SGISC development committee lasted for more than a decade, and because of characteristics that reflect the interests of specific countries, the discussion on which particular phenomena would be included in the new stability criteria was continued. In addition to the pure loss stability, parametric roll, and surf-riding/ broaching modes included in the draft, the excessive acceleration and dead ship modes were added later. Because of the different positions of the experts, there were many conflicting discussions about the prerequisites, especially the definition of incident waves, to establish the criteria for the individual modes. These discussions are still not completely unified and remain as concurrently applicable options, which can be sources of confusion. In some cases, the criteria values for determining the vulnerability have been changed for one criterion.
Therefore, appropriate care should be taken. In particular, the criteria presented in the references have also changed over time, and the application criteria can be changed or deleted, requiring careful attention to a literature search. The history of the regulation discussions can be confirmed in official papers such as IMO (2009a), IMO (2009b), IMO (2012), IMO (2013), IMO (2016a), and IMO (2016b), and this study was also performed by following the criteria provided in these papers.

Among the vulnerable stability modes included so far, the typical vulnerability modes directly related to large ships affecting the shipbuilding industry in Korea are the pure loss of stability and parametric roll modes. The remaining three vulnerable stability modes are excluded from the application target in the case of large ships or are barely related to the Korean shipbuilding industry. Thus, a discussion of these modes is omitted and the above two vulnerable stability modes are covered in this paper.

\subsection{Pure loss of stability}

When a ship in service encounters a wave with a wavelength similar to the length of the ship, and the midship position of the hull is the same as the wavelength, the stability of the hull decreases more rapidly than when the ship is in constant water. The decrease of the stability in this hogging situation in still water is called the pure loss of stability. In sagging, where the center of the hull is located at the wave hollow due to the movement of the wave, the stability increases sharply. However, if a situation in which the stability is repeatedly reduced in the hogging state lasts for a long time, the stability of the hull may be vulnerable

Modern ships, especially container ships and cruise ships, have design conditions that require a large deck area to load many containers or accommodate cabins. In this case, because the change in the water plane according to the height is very large, the shape of the water plane according to the position of the wave is also greatly changed, which causes a pure loss of stability.

\subsubsection{Vulnerability criteria in pure loss of stability (level 1)}

There are two ways to calculate the risk of the pure loss of stability mode. The most basic method is to calculate the metacentric height (GM) value when the hull encounters a steep wave with the same length as the hull. In this method, the GM value is calculated when a wave with $\lambda=L_{P P}$ and $h=\lambda \cdot S_{W}\left(S_{W}=0.0334\right)$ values is located at 10 positions before and after the center point of the hull. Then, it is considered safe when the minimum GM value is greater than and equal to the reference value $\left(R_{P L A}\right)$.

Table 1 SGISC reference documents

\begin{tabular}{cccccc}
\hline & Pure loss of stability & Parametric roll & Broaching & Dead ship condition & Excessive acceleration \\
\hline Definition of criteria & SDC 2/WP.4 & SDC 2/WP.4 & SDC 2/WP.4 & SDC 2/WP.5 & SDC 2/WP.5 \\
(L-1, 2) & Annex 1 & Annex 2 & Annex 3 & Annex 1 & Annex 2 \\
Explanatory notes & SDC 2/WP.5 & SDC 2/WP.5 & SDC 2/WP.5 & SDC 2/WP.5 & SDC 2/WP.5 \\
& Annex 3 & Annex 4 & Annex 5 & Annex 6 & Annex 7 \\
\hline
\end{tabular}




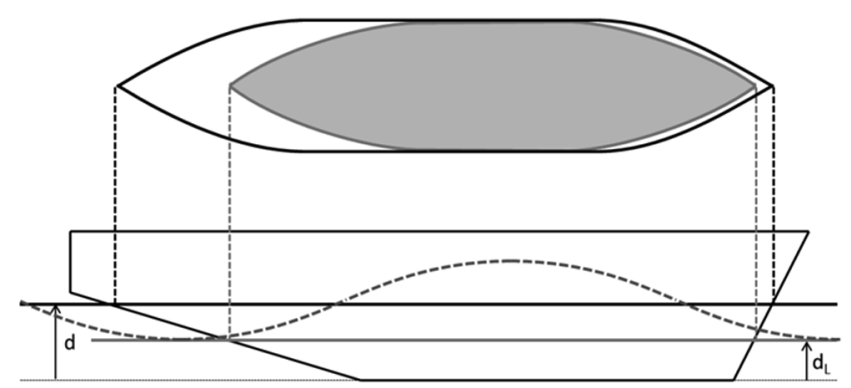

Fig. 3 Definition of drafts for pure loss of stability criteria ( $d$ : draft amidship corresponding to loading condition under consideration, $d_{L}: d-\delta d_{L}$ )

$$
G M_{M I N}>R_{P L A}
$$

Here, the $R_{P L A}$ value is the minimum value of GM, which is a criterion for satisfying level 1 , and is defined as $0.05(\mathrm{~m})$ in the IMO regulation (IMO, 2016b). Another approach is to avoid the complexity of finding the GM value for each wave position and taking into account the trim and settlement in that state. In this method, the ratio between the change in the GM value of the hull and the GM value in still water is calculated. Complexity can be avoided because only the draft at each wave position needs to be considered. In level 1, the change in the GM value is calculated through a simple hull geometric calculation.

$$
\frac{G M_{a}}{G M_{0}} \geq 0.12, G M_{a}=\frac{I_{u p}-I_{l o w}}{2 V}
$$

Here, the moment of inertia at any point $(d)$ above the surface based on the water surface of Fig. 3 is defined as $I_{u p}$, and the moment of inertia at point $\left(d_{L}\right)$ below the water surface is defined as $I_{\text {low }}$.

The draft required for this is defined in Fig. 3 .

\subsubsection{Vulnerability criteria in pure loss of stability (level 2)}

As in other modes, level 2 is a calculation performed only if the level-1 criteria are not met. The calculation is made more realistic and the complexity of the calculation increases. The assessment approach determines the sum of probabilistic risks in waves of various components as the extent of the final vulnerability. According to the existing research results to date, there are two methods for calculating level 2 (option A and option B). Option A uses the stability angle (loll angle) $\phi_{S}$, and option $\mathrm{B}$ uses the original power loss angle (angle of vanishing stability) $\phi_{\nu}$. Because option B is less frequently used than option A as a result of the complexity of the calculation, option A is used in this paper.

In the case of option A, the criteria are represented as $C R 1$ and $C R 2$, and a method is used where a ship is determined to be safe when both of the risk values calculated based on the two criteria are 0.06 or less. This is expressed as follows:

$$
\max (C R 1, C R 2)<0.06
$$

$$
\begin{aligned}
& C R \mathrm{l}=\sum_{i-1}^{N} W_{i} \mathrm{C}_{i} \quad C \mathrm{l}=\left\{\begin{array}{l}
0\left(\phi_{\nu}>30^{\circ}\right) \\
1\left(\phi_{\nu}<30^{\circ}\right)
\end{array}\right. \\
& C R 2=\sum_{i-1}^{N} W_{i} C 2_{i} \quad C 2=\left\{\begin{array}{l}
0\left(\phi_{S}>25^{\circ} \text { or } 15^{\circ}\right) \\
1\left(\phi_{S}<25^{\circ} \text { or } 15^{\circ}\right)
\end{array}\right.
\end{aligned}
$$

where $W_{i}$ is a weighted factor depending on the significant wave factor $(H s)$ and wave period $(T z)$ and is provided in IMO regulation.

The criteria in level 2 of the pure resilience mode are to estimate the hull risk of each probabilistic ocean component as an index of 1 or 0 , multiply the probability value by the risk factor for each component, express the final risk as $C R 1$ and $C R 2$, and determine whether the magnitude of the risk is above a certain value.

$$
C 2_{i}= \begin{cases}1 & \phi_{s}>R_{P L 2 a}=15^{\circ} \text { or } \phi_{\text {loll }}>R_{P L 2 b}=25^{\circ} \\ 0 & \text { otherwise }\end{cases}
$$

This probabilistic assessment necessarily requires a definition of the wave distribution, which covers 16 wave periods and 17 wave heights recommended by the International Association of Classification Societies (IACS) and judges the stability criteria with the stability loss risks in 197 waves that can actually occur. The detailed information on this definition is defined by the IMO (2009a).

Belenky et al. (2011) reported the results of applying the above

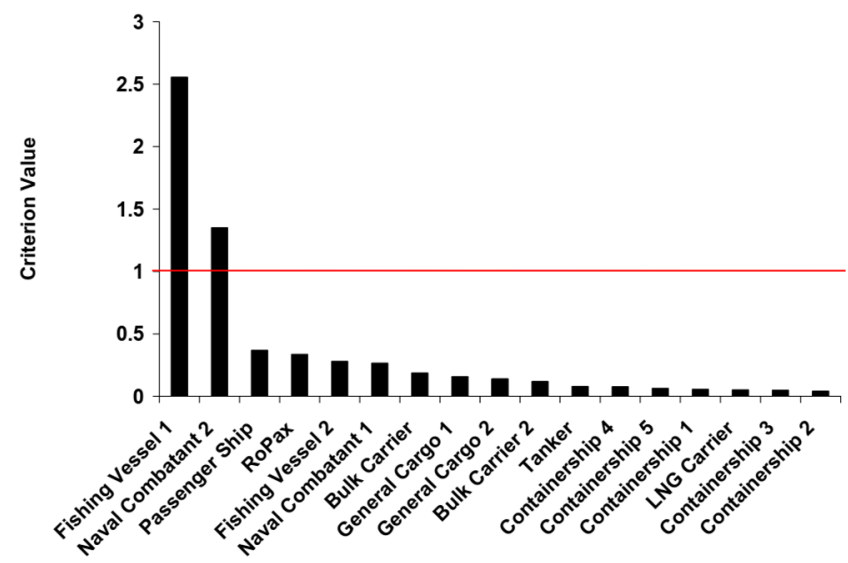

Fig. 4 Calculation result for pure loss of stability ( $C R 1$, level 1)

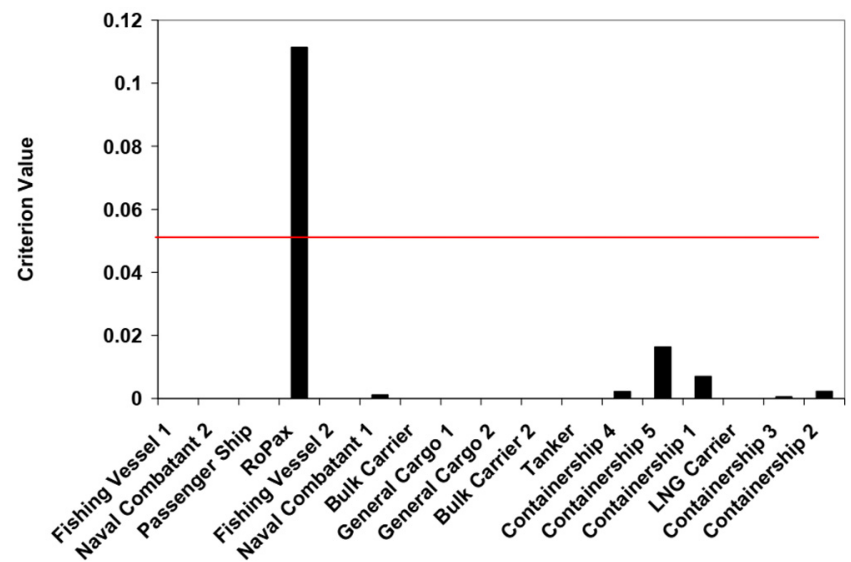

Fig. 5 Calculation result for pure loss of stability ( $C R 2$, level 2$)$ 
Table 2 Example of calculating vulnerability of representative vessels for pure loss of stability (S: satisfied, U: unsatisfied)

\begin{tabular}{|c|c|c|c|c|c|c|c|}
\hline Type & $L$ & $G M$ & $V s$ & $C R 1$ & $\begin{array}{l}\text { Vulnerability } \\
\text { (CR1) }\end{array}$ & $C R 2$ & $\begin{array}{l}\text { Vulnerability } \\
\text { (CR2) }\end{array}$ \\
\hline Fishing vessel 1 (ITTC A2) & 34.5 & 1.97 & 15 & 2.56 & $\mathrm{U}$ & 0.00 & - \\
\hline Naval combatant 2 (ONR TH) & 150 & 1.16 & 15 & 1.35 & $\mathrm{U}$ & 0.00 & - \\
\hline Passenger ship & 276.4 & 3.42 & 15 & 0.37 & $\mathrm{~S}$ & 0.00 & - \\
\hline RoPax & 137 & 0.36 & 15 & 0.34 & S & 0.11 & $\mathrm{U}$ \\
\hline Fishing vessel 2 & 21.56 & 0.51 & 15 & 0.28 & $\mathrm{~S}$ & 0.00 & - \\
\hline Naval combatant 1 (ONR FL) & 150 & 0.20 & 15 & 0.27 & S & 0.00 & $\mathrm{~S}$ \\
\hline Bulk carrier & 275 & 4.19 & 15 & 0.19 & $\mathrm{~S}$ & 0.00 & - \\
\hline General cargo 1 (S60) & 121.9 & 0.15 & 15 & 0.16 & $\mathrm{~S}$ & 0.00 & - \\
\hline General cargo 2 (C4) & 161.2 & 0.15 & 15 & 0.14 & $\mathrm{~S}$ & 0.00 & - \\
\hline Bulk carrier 2 & 145 & 0.15 & 15 & 0.12 & $\mathrm{~S}$ & 0.00 & - \\
\hline Tanker & 320 & 1.72 & 15 & 0.08 & $\mathrm{~S}$ & 0.00 & - \\
\hline Containership 4 & 283.2 & 0.15 & 15 & 0.08 & $\mathrm{~S}$ & 0.00 & $\mathrm{~S}$ \\
\hline Containership 5 (C11) & 262 & 0.15 & 15 & 0.06 & $\mathrm{~S}$ & 0.02 & $\mathrm{~S}$ \\
\hline Containership 1 & 322.6 & 0.15 & 15 & 0.06 & $\mathrm{~S}$ & 0.01 & S \\
\hline LNG carrier & 267.8 & 0.15 & 15 & 0.05 & $\mathrm{~S}$ & 0.00 & - \\
\hline Containership 3 & 330 & 0.15 & 15 & 0.05 & $\mathrm{~S}$ & 0.00 & $\mathrm{~S}$ \\
\hline Containership 2 & 376 & 0.15 & 15 & 0.04 & $\mathrm{~S}$ & 0.00 & $\mathrm{~S}$ \\
\hline
\end{tabular}

vulnerability criteria of pure loss of stability to 17 representative ship models. The results are shown in Table 2, Fig. 4, and Fig. 5.

According to these results, the values of two factors, $C R 1$ and $C R 2$, significantly change with the target ship, and thus the vulnerability in each mode can be determined with clear criteria. Except for fishing vessel 1 and a battleship, which are special kinds of ships, the $C R 1$ values of common merchant ships are evenly distributed. Thus, the difference between the values is not very large, and their distribution is very dichotomous compared to $C R 2$, so that it is easy to see whether or not the criteria are satisfied. In addition, the results also show that the risks of RoPax and container ships are higher than those of other ships, as is generally expected.

\subsection{Parametric roll}

Parametric vibration is a vibration phenomenon that occurs when two vibromotive forces are applied during one vibration cycle (like swinging), and it is a common phenomenon in our daily lives. The parametric roll of a ship is a resonance phenomenon that occurs when the period of the wave incident on the hull is $1 / 2$ of the resonance period of the general roll, which is distinguished from the common roll resonance. Unlike the roll generated in a ship during beam sea runs, it should be noted that parametric rolls may occur when a wave meets one half of the roll resonant period in longitudinal waves.

The resonant frequency of a beam sea occurs at a specific frequency irrespective of wave steepness, but the magnitude of the rolling angle varies with the wave steepness, and parametric roll may occur at twice this frequency. The frequency of the parametric roll has a value twice that of the rolling resonance frequency of the wave, but is also affected by the wave steepness. In particular, a higher wave height tends to widen the frequency at which parametric rolls can occur, which is a good indication that a high wave height increases the likelihood of parametric roll at sea.

In recent years, it is common for the roll resonance period to increase with the size of the vessel. Here, because large resonances can be generated even when large vessels encounter waves with half the resonance period and not reach a very large resonance frequency, it is difficult to occur. For example, the 8000 TEU class container ship "APL China" experienced an accident involving parametric roll, which caused the loss of most of its containers in October of 1998. After this accident, extensive research on the parametric roll phenomenon was conducted, along with extensive research on how to detect signs of parametric roll in advance (ABS, 2004).

The kinematic equation for roll is generally complex with other modes of motion, but the IMO currently recommends interpreting a single degree of freedom motion that only considers roll for parametric rolls. The roll equation of the hull, including the rotational moment of inertia $\left(I_{x}\right)$ of the hull relative to the roll angle $(\phi)$, and the corresponding additional mass $\left(A_{44}\right)$, damping coefficient $\left(B_{44}\right)$, and stability $(W)$ generated during the motion can be expressed as follows:

$$
\left(I_{x}+A_{44}\right) \ddot{\phi}+B_{44} \dot{\phi}+W \cdot G Z(\phi, t)=0
$$

With appropriate assumptions, this equation can be expressed as follows. The mathematical development process for this equation is described in detail in Uzunoglu (2011) and Umeda (2013).

$$
\ddot{\phi}+2 \dot{\phi} \dot{\phi}+\left(\omega_{m}^{2}+\omega_{a}^{2} \cos \left(\omega_{e} t\right)\right) \cdot \phi=0
$$




$$
\omega_{m}=\sqrt{\frac{\Delta \cdot G M_{m}}{I_{x}+A_{44}}} ; \omega_{a}=\sqrt{\frac{\Delta \cdot G M_{a}}{I_{x}+A_{44}}} ; \delta=\frac{1}{2} \frac{B_{44}}{I_{x}+A_{44}}
$$

where $\omega_{e}$ is defined as the encounter frequencies $\omega_{m}, \omega_{a}$ and $\delta$ is defined as in Eq. (8). In Eq. (8), $\Delta$ is the hull displacement, $G M_{m}$ is the mean of the GM values, and $G M_{a}$ is the amplitude of the GM change in the wave.

The roll equation can be expressed by substituting the well-known Mathieu equation as follows:

$$
\begin{aligned}
& \frac{d^{2} x}{d \tau^{2}}+(p+q \cos (\tau)) \cdot x=0 \\
& p=\left(\bar{w}_{m}^{2}-\mu^{2}\right) ; q=\bar{w}_{m}^{2}
\end{aligned}
$$

The behavior of the solution of this nonlinear equation is well known, where the divergence and convergence are very nonlinear, depending on the values of parameter $p$ and $q$, and the behavior of the solution varies significantly even with small parameter changes. This is shown schematically in Fig. 6. The figure illustrates the Ince-Strutt diagram and shows the diverging and non-diverging areas according to the parameter values. It is not easy to predict the diverging area. In the actual calculation of the roll, the roll angle diverges according to a given parameter in some cases. This situation physically corresponds to a situation where a parametric roll occurs and, consequently, a large roll motion occurs.

Another difficulty in predicting parametric roll is the effect of damping. Rolling is dampened by a variety of causes, but it is very difficult to accurately predict each of these factors. Ikeda (2004) conducted a study to systematically analyze the causes of roll damping and developed a practical formula to mathematically express its rough magnitude. Fig. 7 shows an example where the values of the roll are different when the damping is considered and when the damping is not considered. In this figure, it can be seen that the solution considering the nonlinear damping can be stable even though the solution of the linear equation diverges. This result shows that the simplified model has more design margins. Thus, the assessment of the roll tends to be more conservative. It can be seen that applying a more realistic model can be expected to reduce the design margins because the behavior of the solution can be more exactly estimated even though the construction of the mathematical model is complex. Thus, it can be inferred that a more optimized solution can be obtained in the actual design.

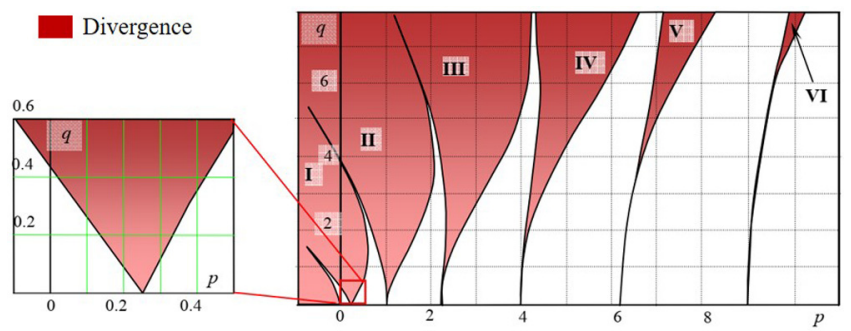

Fig. 6 Ince-Strutt diagram

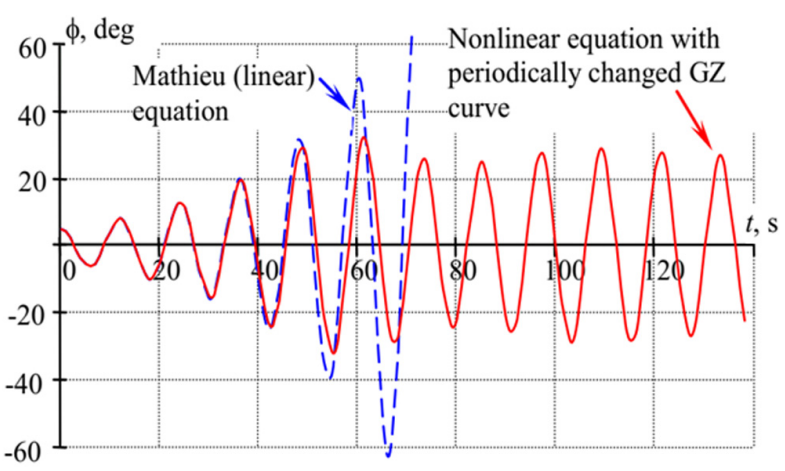

Fig. 7 Effect of nonlinearity on the solution (-: nonlinear equation, - -: Mathieu (linear) equation)

\subsubsection{Acceptance equation of parametric roll stability (level 1)}

Belenky et al. (2011) proposed the following simple acceptance equation through some assumptions about the behavior of the above equations.

$$
\begin{aligned}
& \frac{\Delta G M}{G M} \leq R_{P R} \\
& \Delta G M=\frac{I_{H}-I_{L}}{2 V}, \text { only if } \frac{V_{D}-V}{A_{W}(D-d)} \geq 1.0
\end{aligned}
$$

Here, there are various proposals for the size of $R_{P R}$ for the shape of each ship, which is mainly defined as a value based on the central section coefficient $\left(C_{m}\right) . I$ is the moment of inertia, $V_{D}$ is the volume, $A_{W}$ is the waterline area, and $d$ is the draft. For specific definitions, see Table 3, Table 4 and IMO Regulations (IMO, 2016b).

Fig. 8 shows the level-1 calculation results for parametric rolls. When the criteria value for the assessment is set to $0.49,10$ ship models are judged to be vulnerable, indicating that they do not pass the level-1 criteria at a fairly high rate. The ships in this category have high ship speed characteristics, and most ships judged as vulnerable have a ship speed of $9.26 \mathrm{~m} / \mathrm{s}$ or more. Exceptionally, it is considered that general cargo ships with a ship speed of $8.23 \mathrm{~m} / \mathrm{s}$ were judged to be vulnerable because of the height of the center of gravity. Liquefied

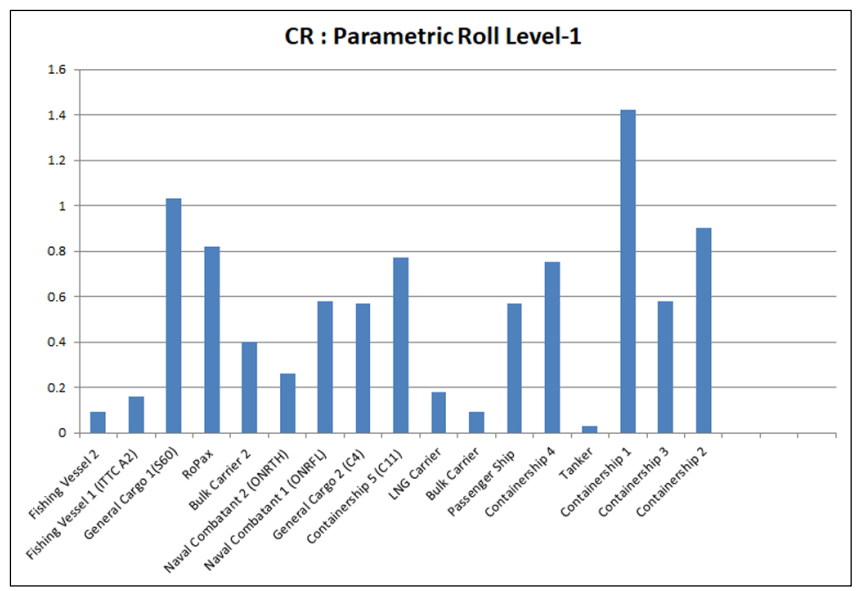

Fig. 8 Parametric roll (level 1) 
Table 3 Principle dimension of sample ships

\begin{tabular}{|c|c|c|c|c|c|}
\hline \multicolumn{2}{|l|}{ Dimensions } & Unit & $1000 \mathrm{TEU}$ & 1040 TEU & 22000 RoPax \\
\hline \multicolumn{2}{|l|}{ LengthOverall: Abt. } & $\mathrm{m}$ & 146.3 & 143.9 & 160 \\
\hline \multicolumn{2}{|l|}{ LengthBetweenPerpendiculars: } & $\mathrm{m}$ & 136.1 & 134.7 & 148 \\
\hline \multicolumn{2}{|l|}{ Breadth(Mld.): } & $\mathrm{m}$ & 22.6 & 22.6 & 24.8 \\
\hline \multicolumn{2}{|l|}{ Depth (Mld.) : } & $\mathrm{m}$ & 11.2 & 11.2 & 14 \\
\hline \multicolumn{2}{|l|}{ Draft (D.L.W.L,Mld.): } & $\mathrm{m}$ & 7.4 & 7.4 & 5.8 \\
\hline \multicolumn{2}{|l|}{ Draft (S.L.W.L,Mld.): } & $\mathrm{m}$ & 8.2 & 8.2 & \\
\hline \multicolumn{2}{|l|}{ Complements: } & $\mathrm{p}$ & 20 & 20 & 48 \\
\hline \multicolumn{2}{|l|}{ Full load displacement: } & $\mathrm{t}$ & $17,773.1$ & $17,981.8$ & $12,422.6$ \\
\hline \multicolumn{2}{|l|}{ Light ship weight: } & $\mathrm{t}$ & 4,838 & 4,543 & 8,621 \\
\hline \multicolumn{2}{|l|}{ Gross tonnage (international): Abt. } & $\mathrm{t}$ & - & 9,930 & 22,000 \\
\hline \multicolumn{2}{|l|}{ AK : B. Keel area } & $\mathrm{m}^{2}$ & 13.9 & 13.9 & 60 \\
\hline \multicolumn{2}{|l|}{ LWL } & $\mathrm{m}$ & 136.1 & 134.7 & 148 \\
\hline \multicolumn{2}{|l|}{ B (ext) } & $\mathrm{m}$ & 22.6 & 22.6 & 24.8 \\
\hline \multicolumn{2}{|l|}{ Btm shell thick $=$} & $\mathrm{m}$ & 0.014 & 0.014 & 0.014 \\
\hline Speed & $\max$ & $\mathrm{m} / \mathrm{s}$ & & & \\
\hline Speed & service & $\mathrm{m} / \mathrm{s}$ & 9.26 & 9.26 & 10.29 \\
\hline Power & MCR & $\mathrm{kW}$ & 8280 & 8280 & 13920 \\
\hline Power & NCR & $\mathrm{kW}$ & 7452 & & \\
\hline Dia of propeller & $\mathrm{m}$ & $\mathrm{m}$ & 5.6 & 5.4 & 4.3 \\
\hline$L a$ & $\mathrm{~m}$ & $\mathrm{~m}$ & 2.55 & 2.725 & 3 \\
\hline$h s$ & $\mathrm{~m}$ & $\mathrm{~m}$ & 0.2 & 0.2 & 0.05 \\
\hline
\end{tabular}

Table 41040 TEU CV pure loss of stability and parametric roll (Level-1)

\begin{tabular}{|c|c|c|c|c|c|c|c|c|c|c|}
\hline & Draft & 5.238 & 5.029 & 4.860 & 8.214 & 8.115 & 8.134 & 8.214 & 8.157 & 8.134 \\
\hline \multicolumn{2}{|c|}{ only if, $\left(V_{D^{-}}-V\right) / A_{W}(D-d) \geq 1.0$} & 1.17 & 1.18 & 1.19 & 1.06 & 1.06 & 1.06 & 1.06 & 1.06 & 1.06 \\
\hline$V_{D}$ & Displacement volume $\left(\mathrm{m}^{3}\right)$ & 25501 & 25501 & 25501 & 25501 & 25501 & 25501 & 25501 & 25501 & 25501 \\
\hline$A_{W}$ & Area of water plane $\left(\mathrm{m}^{2}\right)$ & 2238.0 & 2213.0 & 2194.0 & 2675.7 & 2661.7 & 2664.5 & 2675.7 & 2667.9 & 2664.5 \\
\hline$I_{L}=$ & $\begin{array}{l}\text { Second Moment of the water } \\
\text { plane at the draft } d_{L}\left(\mathrm{~m}^{4}\right)\end{array}$ & 62284 & 61146 & 59961 & 82869 & 82364 & 82574 & 82794 & 82596 & 82501 \\
\hline$K B$ & $\begin{array}{c}\text { Center of buoyancy in height } \\
\text { direction }\end{array}$ & 2.827 & 2.707 & 2.819 & 4.497 & 4.439 & 4.451 & 4.497 & 4.464 & 4.451 \\
\hline$G M_{\min }=$ & $\begin{array}{c}=K B+\left(I_{L} / V\right)-V C G \\
=K B+\left(I_{L} /\left(C_{b} \times L_{P P} \times B \times d\right)-V C G\right.\end{array}$ & 3.292 & 3.451 & 3.684 & -0.044 & -0.021 & 0.015 & -0.059 & 0.013 & -0.001 \\
\hline \multirow[t]{2}{*}{ criteria $_{P L A}$} & $R_{P L} A=\left[\min \left(1.83 d(F n)^{2}, 0.05\right] \mathrm{m}\right.$ & 0.05 & 0.05 & 0.05 & 0.05 & 0.05 & 0.05 & 0.05 & 0.05 & 0.05 \\
\hline & $1.83 d(F n)^{2}=$ & 0.622 & 0.597 & 0.577 & 0.975 & 0.963 & 0.966 & 0.975 & 0.968 & 0.966 \\
\hline$G M \min >R_{P L A}$ & Result (Pure loss of stability L-1) & Safe & Safe & Safe & Danger & Danger & Danger & Danger & Danger & Danger \\
\hline \multicolumn{2}{|c|}{$\triangle G M / G M$ is calculated as follows: } & 5.514 & 5.463 & 5.379 & 0.991 & 0.982 & 0.998 & 0.98 & 1.022 & 0.987 \\
\hline \multicolumn{2}{|c|}{$\begin{array}{c}\Delta G M=\left(I_{H} I_{L}\right) /(2 V) \\
=\left(I_{H}-I_{L}\right) /\left(2 \times C_{b} \times L_{p p} \times B \times d\right)\end{array}$} & 1.676 & 1.732 & 1.796 & 0.923 & 0.938 & 0.932 & 0.925 & 0.931 & 0.934 \\
\hline \multicolumn{2}{|r|}{$\Delta G M / G M=$} & & 0.317 & 0.334 & 0.931 & 0.956 & 0.934 & 0.944 & 0.911 & 0.947 \\
\hline \multicolumn{2}{|c|}{ Result (Parametric Roll L-1) } & & Safe & Safe & Danger & Danger & Danger & Danger & Danger & Danger \\
\hline
\end{tabular}


natural gas (LNG) carriers with a relatively high speed $(9.26 \mathrm{~m} / \mathrm{s})$ are considered to be stable because of their low center of gravity, based on the nature of the cargo.

\subsubsection{Acceptance equation of parametric roll stability (level 2)}

Like the pure loss of stability mode, the vulnerability of parametric rolls can also be found using the probabilistic approach, and the calculation procedures are not different from those of level 1 . However, in the case of level 2 for parametric rolls, very fine calculations are required to avoid the large design margins caused by excessive conservation. It should be noted that two methods (level $2 \mathrm{~A}$ and level 2B) are jointly used because of different opinions between experts on how to evaluate parametric roll. To date, a ship has been recognized as passing the stability criteria if it passes one of these two methods. Thus, level 2B is executed only if level 2A fails. As a result, it has the same effect as setting two levels again inside level 2.

In level 2, the same calculation as in level 1 is performed. In practice, however, the degree of risk for each wave at a given sea level is calculated and the weight of the wave is multiplied by this value. After that, the final degree of vulnerability, $\mathrm{C} 1$, is calculated to judge whether or not this value is above the criteria value.

$$
\begin{aligned}
& C=\sum_{I=1}^{n} W_{i} C_{i} \leq R_{P R 0} \\
& G M\left(H_{i}, \lambda_{i}\right)>0, \frac{\Delta G M\left(H_{i}, \lambda_{i}\right)}{G M\left(H_{i}, \lambda_{i}\right)}<R_{P R}
\end{aligned}
$$

The level-2B approach for parametric roll evaluates the risk by averaging the values in each of the seven directions, taking into account the risk elements along the wave direction.

$$
C 2=\left[\sum_{i=1}^{3} C 2\left(F n_{i}, \beta_{h}\right)+C 2\left(0, \beta_{h}\right)+\sum_{i=1}^{3} C 2\left(F n_{i}, \beta_{f}\right)\right] / 7
$$

The detailed wave information on this method is defined by the IMO (2009a).

In this paper, the main dimensions of ships designed and built by Korea Maritime Services (KMS) are listed in Table 3, and the parametric roll calculation results for the target ships are listed in Table 4, Table 5, and Table 6 . The results of this assessment can be clearly seen by plotting the results (Fig. 9). In the case of the level-2B method, the integral process of the differential equations is essential. In this process, different results are reported depending on whether the nonlinear terms are taken into account. In this paper, the results of each of the two methods applied are displayed and compared.

The calculation results show that the size of the roll angle is always small when the nonlinear terms are considered. This result means that more detailed calculations are a means to eliminate excessive conservatism. The calculated linear/nonlinear results show that high-speed ships with high centers of gravity such as container ships, RoPax, and passenger ships tend to be significantly vulnerable to parametric rolls.

It should be noted that, through levels 1 and 2, the vulnerability to parametric roll is generally greater than the vulnerability to pure loss of stability. Accordingly, it is necessary for shipbuilders to recognize that parametric roll is the most important mode to check during design. At the same time, in the eyes of ship operators such as shipping companies, the capacity of the cargo to be loaded on new ships should be reduced because of the vulnerability to parametric roll in order to reduce the ship's operating speed or lower the center of gravity compared to the current ships in accordance with the new stability criteria.

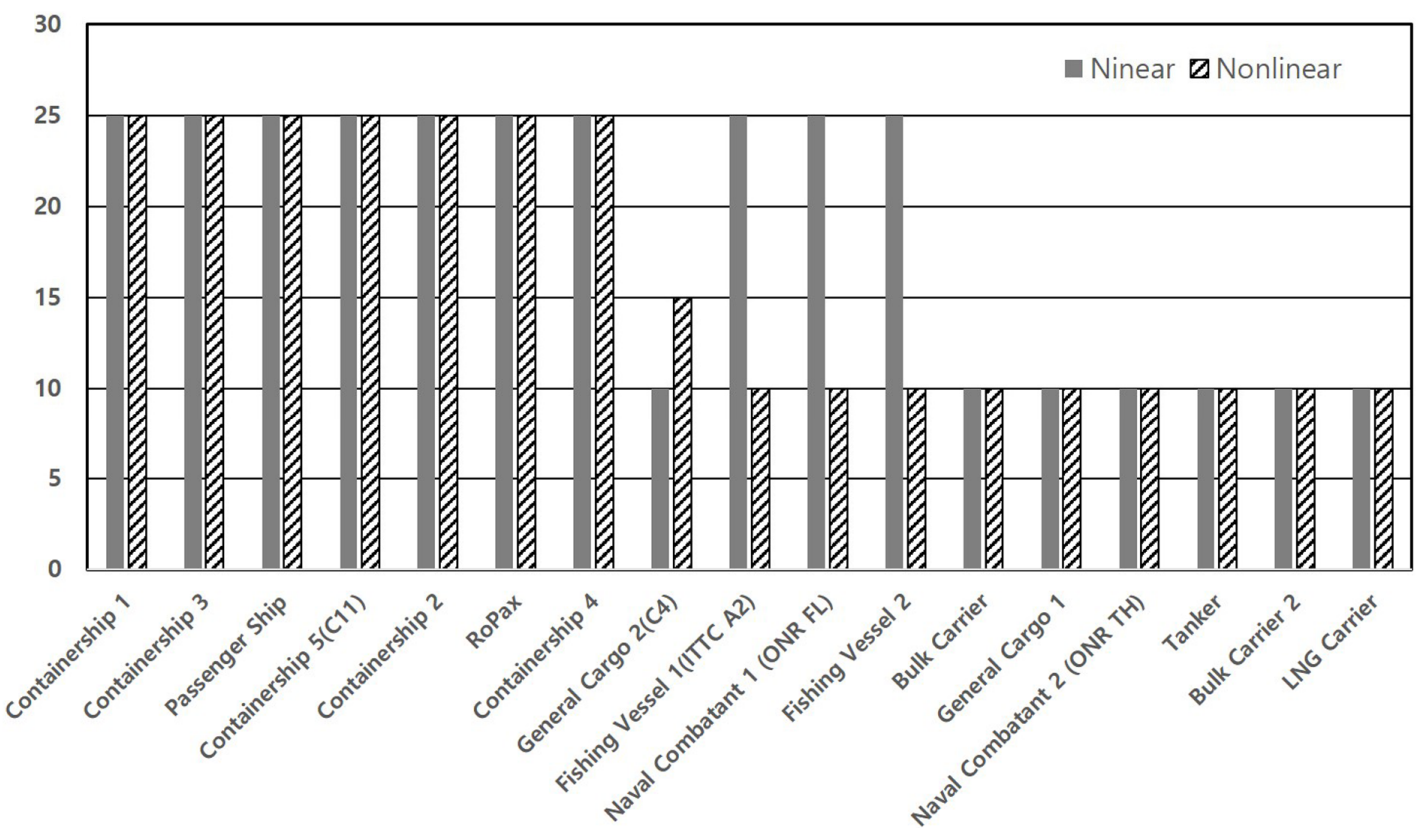

Fig. 9 Parametric roll angle (Level-2) 
Table 51000 TEU CV pure loss of stability and parametric roll (Level-1)

\begin{tabular}{|c|c|c|c|c|c|c|c|c|c|c|}
\hline & Draft & 13.9 & 13.9 & 13.9 & 13.9 & 13.9 & 13.9 & 13.9 & 13.9 & 13.9 \\
\hline \multicolumn{2}{|c|}{ only if, $\left(V_{D^{-}}-{ }\right) / A_{W}(D-d) \geq 1.0$} & 1.17 & 1.18 & 1.18 & 1.05 & 1.06 & 1.05 & 1.05 & 1.06 & 1.05 \\
\hline$V_{D}$ & Displacement volume $\left(\mathrm{m}^{3}\right)$ & 25851.1 & 25851.1 & 25851.1 & 25851.1 & 25851.1 & 25851.1 & 25851.1 & 25851.1 & 25851.1 \\
\hline$A_{W}$ & Area of water plane $\left(\mathrm{m}^{2}\right)$ & 2273.0 & 2260.4 & 2250.1 & 2706.8 & 2704.4 & 2705.2 & 2706.9 & 2703.4 & 2707.9 \\
\hline $\mathrm{R}_{L}=$ & $\begin{array}{l}\text { Second Moment of the water plane } \\
\text { at the draft } d_{L}\left(\mathrm{~m}^{4}\right)\end{array}$ & 63354 & 62929 & 62465 & 84260 & 84275 & 84245 & 84120 & 84150 & 84393 \\
\hline $\mathrm{R} B$ & $\begin{array}{c}\text { Center of buoyancy in height } \\
\text { direction }\end{array}$ & 2.842 & 2.783 & 2.732 & 4.490 & 4.479 & 4.483 & 4.491 & 4.475 & 4.494 \\
\hline$G M_{\min }=$ & $\begin{array}{c}=K B+\left(I_{L} / V\right)-V C G \\
=K B+\left(I_{L} /\left(C_{b} \times L_{P P} \times B \times d\right)-V C G\right.\end{array}$ & 2.806 & 2.997 & 3.118 & -0.007 & 0.106 & 0.162 & 0.090 & 0.206 & 0.319 \\
\hline \multirow[t]{2}{*}{ criteria $_{P L A}$} & $R_{P L} A=\left[\min \left(1.83 d(F n)^{2}, 0.05\right] \mathrm{m}\right.$ & 0.05 & 0.05 & 0.05 & 0.05 & 0.05 & 0.05 & 0.05 & 0.05 & 0.05 \\
\hline & $1.83 d(F n)^{2}=$ & 0.621 & 0.608 & 0.597 & 0.965 & 0.963 & 0.963 & 0.965 & 0.962 & 0.965 \\
\hline \multicolumn{2}{|c|}{$G M m i n>R_{P L A}$ Result (Pure loss of stability L-1) } & Safe & Safe & Safe & Danger & Safe & Safe & Safe & Safe & Safe \\
\hline \multicolumn{2}{|c|}{$\triangle G M / G M$ is calculated as follows: } & 5.292 & 5.309 & 5.285 & 0.943 & 1.038 & 1.094 & 0.797 & 1.131 & 1.223 \\
\hline \multicolumn{2}{|c|}{$\begin{array}{c}\Delta G M=\left(I_{H}-I_{L}\right) /(2 \mathrm{~V}) \\
=\left(I_{H}-I_{L}\right) /\left(2 \times C_{b} \times L_{p p} \times B \times d\right)\end{array}$} & 1.673 & 1.694 & 1.717 & 0.911 & 0.911 & 0.912 & 0.915 & 0.915 & 0.907 \\
\hline \multicolumn{2}{|r|}{$\Delta G M / G M=$} & 0.316 & 0.319 & 0.325 & 0.966 & 0.878 & 0.833 & 1.148 & 0.809 & 0.742 \\
\hline \multicolumn{2}{|r|}{ Result (Parametric Roll L-1) } & Safe & Safe & Safe & Danger & Danger & Danger & Danger & Danger & Danger \\
\hline
\end{tabular}

Table 6 GT 22,000 Ton class RoPax pure loss of stability and parametric roll (Level-1)

\begin{tabular}{|c|c|c|c|c|c|c|c|c|c|c|}
\hline & Draft & 1.26 & 1.28 & 1.29 & 1.13 & 1.17 & 1.17 & 1.26 & 1.28 & 1.28 \\
\hline \multicolumn{2}{|c|}{ only if, $\left(V_{D^{-}} V\right) / A_{W}(D-d) \geq 1.0$} & 41043.9 & 41043.9 & 41043.9 & 41043.9 & 41043.9 & 41043.9 & 41043.9 & 41043.9 & 41043.9 \\
\hline$V_{D}$ & Displacement volume $\left(\mathrm{m}^{3}\right)$ & 2723.9 & 2676.4 & 2631.2 & 3079.2 & 2966.5 & 2966.5 & 2720.7 & 2667.2 & 2667.2 \\
\hline$A_{W}$ & Area of water plane $\left(\mathrm{m}^{2}\right)$ & 74837.88 & 73570.96 & 71293.18 & 88414.44 & 87548.38 & 87548.38 & 77499.16 & 76183.94 & 76183.94 \\
\hline$I_{L}=$ & $\begin{array}{l}\text { Second Moment of } \\
\text { the water plane at } \\
\text { the draft } d_{L}\left(\mathrm{~m}^{4}\right)\end{array}$ & 2.834 & 2.730 & 2.624 & 3.240 & 3.128 & 3.128 & 2.826 & 2.708 & 2.708 \\
\hline$K B$ & $\begin{array}{l}\text { Center of buoyancy in } \\
\text { height direction }\end{array}$ & -0.430 & -0.610 & -0.895 & -0.379 & -0.523 & -0.604 & -0.374 & -0.560 & -0.657 \\
\hline$G M_{\min }=$ & $\begin{array}{c}=K B+\left(I_{L} / V\right)-V C G \\
=K B+\left(I L /\left(C_{b} \times L_{P P} \times B \times d\right)\right. \\
-V C G\end{array}$ & 0.05 & 0.05 & 0.05 & 0.05 & 0.05 & 0.05 & 0.05 & 0.05 & 0.05 \\
\hline \multirow[t]{2}{*}{ criteria $_{P L A}$} & $\begin{array}{c}R_{P L} A= \\
{\left[\min \left(1.83 d(F n)^{2}, 0.05\right] \mathrm{m}\right.}\end{array}$ & 0.672 & 0.648 & 0.623 & 0.762 & 0.738 & 0.738 & 0.670 & 0.643 & 0.643 \\
\hline & $1.83 d(F n)^{2}=$ & Danger & Danger & Danger & Danger & Danger & Danger & Danger & Danger & Danger \\
\hline$G M m i n>R_{P L A}$ & $\begin{array}{l}\text { Result (Pure loss of } \\
\text { stability L-1) }\end{array}$ & Safe & Safe & Safe & Danger & Safe & Safe & Safe & Safe & Safe \\
\hline \multicolumn{2}{|c|}{$\Delta G M / G M$ is calculated as follows: } & 3.245 & 3.107 & 2.915 & 3.074 & 2.969 & 2.888 & 3.121 & 3.01 & 2.868 \\
\hline \multicolumn{2}{|c|}{$\begin{array}{c}\Delta G M=\left(I_{H}-I_{L}\right) /(2 \mathrm{~V}) \\
=\left(I_{H}-I_{L}\right) /\left(2 \times C_{b} \times L_{p p} \times B \times d\right)\end{array}$} & 3.807 & 3.992 & 4.247 & 2.829 & 2.950 & 2.950 & 3.685 & 3.883 & 3.883 \\
\hline \multicolumn{2}{|c|}{$\Delta G M / G M=$} & 1.173 & 1.285 & 1.457 & 0.920 & 0.994 & 1.021 & 1.181 & 1.290 & 1.354 \\
\hline \multicolumn{2}{|c|}{ Result (Parametric Roll L-1) } & Danger & Danger & Danger & anger & Danger & Danger & Danger & Danger & Danger \\
\hline
\end{tabular}

\section{Example of Korean Ship Stability Vulnerability Mode Calculation}

The achievements of global researchers on $2^{\text {nd }}$ generation stability are enormous, but because there are many types of ships with a wide range of sizes, there is a limit to the use of these results by Korean shipbuilding officials. It is considered that looking at the results for previous ships in relation to second generation stability will be of practical help to those in Korea.

The results of level-1 calculations for the pure loss of stability and parametric roll modes are listed in Table 4, Table 5, and Table 6. Because of the characteristics of container ships, they have various 
loading conditions. However, this paper covers typical loading conditions. In particular, the draft is calculated by taking into account the weight difference between departure and arrival, including changes in draft according to the operation of the hull. In this research, it was found that the assessment of the vulnerability of pure stability occurred at level 2 under the conditions that the load and draft both increased. Each linear parameter is estimated using linearized interpolation, but the results show very reasonable results. In the case of container ships, because the change in the up and down direction of the bow of a full ship is large, and the shape of the water plane significantly changes according to the draft, there is a high possibility of a pure loss of stability. Based on these calculations, it is possible to consider how to reduce the ship's operating speed and Froude number in order to improve the vulnerability of the pure loss of stability mode from the hull design point of view. First, let us consider a method that increases the hull in order to reduce the Froude number. If the length of the ship is increased from $134.7 \mathrm{~m}$ to $153.5 \mathrm{~m}$, with the speed fixed at $9.26 \mathrm{~m} / \mathrm{s}$, the Froude number will be reduced from 0.255 to 0.239 , which will pass the vulnerability test at level 1 . However, it is not realistic to increase the length of the hull. In contrast, let us consider that the ship's operating speed is reduced in order to reduce the Froude number. If the ship speed is reduced from $9.26 \mathrm{~m} / \mathrm{s}$ to $8.23 \mathrm{~m} / \mathrm{s}$, with the length of the ship fixed at $134.7 \mathrm{~m}$, the Froude number can be reduced to the desired level. Therefore, this is a more realistic alternative. As a solution from the operation side, we can think of a method to lower the center of gravity by approximately $10 \mathrm{~cm}$. It might be possible to accomplish this by reducing the container capacity. When considering the movement of the desired center of gravity, it is necessary to sacrifice the first stage of the container loading layer. Because reducing the container loading capacity is a very important problem for the ship owner, it is conceivable to move the center of gravity downward by loading all of the empty containers on top as a solution that does not reduce the container loading capacity. However, this method should be considered with great care because it acts as a factor that greatly affects the unloading order. Finally, the center of gravity can be moved downward with the ballast water. This method can also be considered as a secondary solution because it can only be linked to the total container load capacity and requires careful calculation, and the distance to move the center of gravity is limited.

Three ships were found to be vulnerable to parametric roll, which was expected to some extent. In the case of container ships and RoPax ships, a considerably high center of gravity is inevitable because of the presence of structures such as cargo or cabins on the upper deck. Because of the nature of the ship, if the center of gravity is made extremely low, its movement will be limited because an increase in the roll acceleration is expected to damage the cargo or adversely affect the health of the crew. As a way to improve the vulnerability to parametric roll, reducing the change in the water plane configuration subject to the change in the draft is a basic method to reduce the difference in the moment of inertia $\left(I_{H}-I_{L}\right)$. However, it is very difficult to introduce such a cylindrical ship model when considering the resistance/propulsion performance. It is locally possible to consider increasing the bilge-kill area, but this is considered to be a limited solution because of the limited bilge-kill space.

In this study, negative results were obtained in most cases when assessing vulnerabilities applying level 1 criteria, but these results mean that more detailed research is needed through level 2, and more realistic assessments can be expected from level-2 research. In the case of parametric rolls, however, it is considered that significant changes are required for all three ship models, along with more careful calculations, including a three-step direct assessment method.

\section{Summary and conclusion}

This paper examined the current international research trends for the second generation of stability criteria and briefly summarized the physical background of each mode and the mathematical modeling procedure. In particular, in view of the fact that Korean shipbuilders mainly build large ships, this paper discussed the pure loss of stability mode and parametric roll mode, which are very relevant for Korean shipbuilders, leaving out the modes that are very unlikely to occur in large ships or that are already excluded from the calculation in the regulations themselves.

In the case of the pure loss of stability mode, it has been shown that the ships in question are often not large problems even if they are designed according to the current criteria, but in the case of parametric roll, the ships may often fail to meet the vulnerability criteria. In particular, container ships, which represent one of the most important ship models in the Korean shipbuilding industry, have frequently been found to fail to meet the vulnerabilities of the parametric roll mode depending on the loading conditions. Consequently, appropriate measures are considered to be required. The conclusions are summarized as follows:

(1) In order to prevent the loss of life and cargo due to the occurrence of various marine accidents, the IMO is developing the second generation of stability criteria to improve the stability of ships, which will ensure that a ship has sufficient stability even in waves. The new stability criteria are in addition to the existing stability criteria, which will remain in effect even after the new stability criteria are put in place.

(2) Regarding the stability in waves, the criteria for five modes are being developed. The inspection structure is composed of a multi-layer structure to minimize the calculations used to verify whether or not the stability criteria are satisfied. The calculations to verify the criteria have been minimized. That is, at a low level, the criteria are verified by simple calculations, and as the level becomes higher, more complicated and detailed verification is performed. If the criteria are satisfied at the low level, the calculation for the next level is not performed. In general, because the lower level involves a greater design margin, vulnerabilities are conservatively assessed and the assessment results are unfavorable for optimization.

(3) At level 1, which is the lowest level, the stability is assessed in a 
very simple way. However, at level 2 , a more complex method is introduced to assess the stability by determining the probabilistic vulnerability.

(4) Level 3 performs very detailed calculations by performing direct simulations, but this level requires a program with a high level of calculation. The specifications for this calculation program are under discussion. However, in general, a reasonable computer program requires a relatively long calculation time, and thus the development of a technique for determining the stability of a ship within a practical time is required.

(5) When reviewing the results of applying the second generation of stability criteria to the previous ships built in Korea in various cases, it seems that the ships built under the current criteria do not meet the stability criteria in many cases and there is no choice but to operate the ships in a state where the ship speed, dead weight capacity, and other factors are limited. Therefore, it is considered that appropriate design changes are needed to meet the new stability criteria.

\section{Acknowledgments}

This paper was prepared with the support of the Korea Institute of Marine Science \& Technology Promotion (KIMST) and financed by the Ministry of Maritime Affairs and Fishers (Development of IMO's second generation intact stability verification technology for improving ship stability 20180318).

\section{References}

American Bureau of Shipping (ABS). (2004). Guide for the Assessment of Parametric Roll Resonance in the Design Of Container Carriers. Houston, USA; American Bureau of Shipping.

Belenky, V., Bassler, C.G., \& Spyrou, K.J. (2011). Development of Second Generation Intact Stability Criteria (NSWCCD-50-TR2011/065). Naval Surface Warfare Center Carderock Division, US Navy.

Chouliaras, S. (2014). Evaluation of IMO'S Second Generation Intact Stability Criteria (M.S. Thesis). National Technical University of Athens, Athens, Greece.

Grinnaert, F. (2017). Analysis and Implementation of Second Generation Criteria in a Stability Computer Code (Ph.D. Thesis) Université de Bretagne Occidentale (UBO), Brest, France.

Ikeda, Y. (2004). Prediction Methods of Roll Damping of Ships and Their Application to Determine Optimum Stabilization Devices. Marine Technology, 41(2), 89-93.

International Maritime Organization (IMO). (2009a). International Code of Intact Stability. Development of Second Generation Intact Stability Criteria, London.

International Maritime Organization (IMO). (2009b). Information Collected by the Intersessional Correspondence Group on Intact Stability. SLF 52/INF.2, Submitted by USA, London, England.
International Maritime Organization (IMO). (2012). Proposal of Revision of Updated Draft Vulnerability Criteria of Levels 1 and 2 for the Failure Modes of Pure Loss of Stability and Prametric Rll. SLF ISCG 54/19, Submitted by Japan, London, England.

International Maritime Organization (IMO). (2013). Information Cllected by the Correspondence Group on Intact Stability Rgarding the Scond Gneration Itact Sability Citeria Dvelopment, SDC 1/INF.8, Submitted by Japan, London, England.

International Maritime Organization (IMO). (2016a). Finalization of Second Generation Intact Stability Criteria, Amendments to Part $\mathrm{B}$ of the 2008 IS Code on Towing, Lifting and Anchor Handling Operations. SDC 3/WP.5, 3rd Session.

International Maritime Organization(IMO). (2016b). Observations Rgarding the Fasibility of the Crrent Vrsion of the Lvel 2 Citerion for Parametric roll in the Second Generation Intact Stability Citeria. Submitted by Sweden, London England.

Krüger S., Hatecke H., Billerbeck H., Bruns A., \& Kluwe F. (2013). Investigation of the 2nd Generation of Intact Stability Criteria for Ships Vulnerable to Parametric Rolling in Following Seas. Proceedings of ASME 2013 32nd International Conference on Ocean, Offshore and Arctic Engineering, Nantes France, 10353-10363. https://doi.org/10.1115/OMAE2013-10353

Peters, W., Belenky, V., Bassler, C., Spyrou, K.J., Umeda, N., Bulian, G., \& Altmayer, B. (2011). The Second Generation Intact Stability Criteria: An Overview of Development. Proceedings of SNAME Annual Meeting and Expo - Society of Naval Architects and Marine Engineers, Houston, USA.

Rahola, J. (1939). The Judging of the Stability of Ships and the Determination of the Minimum Amount of Stability Especially Considering the Vessels Navigating Finnish Water (Ph.D. Thesis). Technical University of Finland, Helsinki Finland.

Umeda, N. (2013). Current Status of Second Generation Intact Stability Criteria Development and Some Recent Efforts. Proceedings of the 13th International Ship Stability Workshop, Brest, France, 138-157.

Uzunoglu, C.E. (2011). Numerical and Experimental Study of Parametric Rolling of a Container Ship in Waves (Master's Thesis). Technical University of Lisbon, Lisbon, Portugal.

\section{Author ORCIDs and Contributions}
Author name
ORCID
Contributions
Chung, Jaeho
0000-0003-1975-3435
(1)(2)(3)(4)(5)
Shin, Dong Min
$0000-0002-9287-9803$
(3) (4)
Kim, Won-Don
0000-0002-8892-064X
(2)
Moon, Byung Young
0000-0002-3935-504X
(5)
(1) Conceived of the presented idea or developed the theory
(2) Carried out the experiment or collected the data
(3) Performed the analytic calculations or numerical simulations
(4) Wrote the manuscript
(5) Supervised the findings of this study 